\title{
How do COPD comorbidities affect ICU outcomes?
}

This article was published in the following Dove Press journal: International Journal of COPD

17 October 2014

Number of times this article has been viewed

\section{Esra Akkutuk Ongel \\ Zuhal Karakurt \\ Cuneyt Salturk \\ Huriye Berk Takir \\ Bunyamin Burunsuzoglu \\ Feyza Kargin \\ Gulbanu H Ekinci \\ Ozlem Mocin \\ Gokay Gungor \\ Nalan Adiguzel \\ Adnan Yilmaz}

Respiratory Intensive Care Unit Clinic, Sureyyapasa Chest Diseases and Thoracic Surgery Teaching and Research Hospital, Istanbul, Turkey
Correspondence: Cuneyt Salturk Merdivenkoy mahallesi Ortabahar sokak hakan apt.no: 15 d: 16 Kadikoy 34732, Istanbul, Turkey

Tel +90505 50l7242

Email csalturk@yahoo.com
Background and aim: Chronic obstructive pulmonary disease (COPD) patients with acute respiratory failure (ARF) frequently require admission to the intensive care unit (ICU) for application of mechanical ventilation (MV). We aimed to determine whether comorbidities and clinical variables present at ICU admission are predictive of ICU mortality.

Methods: A retrospective, observational cohort study was performed in a tertiary teaching hospital's respiratory ICU using data collected between January 2008 and December 2012. Previously diagnosed COPD patients who were admitted to the ICU with ARF were included. Patients' demographics, comorbidities, body mass index (BMI), ICU admission data, application of noninvasive and invasive MV (NIV and IMV, respectively), cause of ARF, length of ICU and hospital stay, and mortality were recorded from their files. Patients were grouped according to mortality (survival versus non-survival), and all the variables were compared between the two groups.

Results: During the study period, a total of 1,013 COPD patients (749 male) with a mean age (standard deviation) of $70 \pm 10$ years met the inclusion criteria. Comorbidities of the nonsurvival group (female/male, 40/131) were significantly higher compared with the survival group (female/male, 224/618): arrhythmia (24\% vs 11\%), hypertension (42\% vs 34\%), coronary artery disease (28\% vs $11 \%)$, and depression ( $7 \%$ vs $3 \%)(P<0.001, P<0.035, P<0.001$, and $P<0.007$, respectively). Logistic regression revealed the following mortality risk factors: need of IMV, BMI $<20 \mathrm{~kg} / \mathrm{m}^{2}$, pneumonia, coronary artery disease, arrhythmia, hypertension, chronic hypoxia, and higher acute physiology and chronic health evaluation II (APACHE II) scores. The respective odds ratios, confidence intervals, and $P$-values for each of these were as follows: $27.7,15.7-49.0, P<0.001 ; 6.6,3.5-412.7, P<0.001 ; 5.1,2.9-8.8, P<0.001 ; 2.9$, $1.5-5.6, P<0.001 ; 2.7,1.4-5.2, P<0.003 ; 2.6,1.5-4.4, P<0.001 ; 2.2,1.2-3.9, P<0.008$; and $1.1,1.03-1.11, P<0.001$.

Conclusion: Patients with severe COPD and cardiac comorbidities and cachexia should be closely monitored in ICU due to their high risk of ICU mortality.

Keywords: comorbidity, chronic obstructive pulmonary disease, intensive care unit

\section{Introduction}

The prevalence of chronic obstructive pulmonary disease (COPD) ranges from $8 \%$ to $20 \%$ worldwide. ${ }^{1}$ Decelerated disease progression, increased quality of life, and reduced rates of hospitalization have been achieved with current COPD treatment approaches..$^{2-4}$ However, intensive care unit (ICU) admission may be required due to disease progression, exacerbation, and respiratory failure. Priority application of noninvasive mechanical ventilation (NIV) is associated with a significantly decreased ICU mortality of COPD patients. ${ }^{5}$ Despite advances, ICU 
treatment outcomes are not always successful with NIV treatment; patient comorbidities may play an important role in survival.

Cardiovascular diseases, diabetes mellitus (DM), hypertension, osteoporosis, psychiatric diseases (anxiety and depression), metabolic syndrome, lung cancer, and infections are defined as COPD-related comorbidities. ${ }^{6}$ Although the need for ICU admission is thought to be due to disease progression, there is no clear relationship with these comorbidities and ICU demand. The presence of comorbidities are known to be associated with a deteriorated course of COPD; ${ }^{6}$ however, there is limited data regarding the reasons for respiratory failure in COPD patients and the effect of these comorbidities on ICU outcome.

This study was designed to investigate the causes of mortality in COPD patients admitted to the ICU, the presence of comorbidities, and their effect on mortality. The research was conducted in the respiratory ICU of a tertiary chest disease training and research hospital in which 1,050 patients with respiratory failure were followed annually.

\section{Methods}

We designed a retrospective, observational, cohort study in a 22-bed, level III ICU of a tertiary teaching hospital for chest diseases, thoracic surgery center between January 1, 2008 and December 31, 2012. This chest diseases center is a reference hospital for only the Anatolian Region of Turkey. During the study period, a total of eight intensivist specialists worked in the ICU, which they staffed 24 hours a day. The study was approved by the local ethics committee of Kartal Lutfi Kirdar Teaching and Research Hospital, Istanbul, Turkey. Ethical approval was in accordance with the Declaration of Helsinki. Due to the retrospective nature of the study design, informed consent was not obtained.

\section{Patients}

We included consecutive patients with previously diagnosed COPD who were admitted to our ICU due to acute respiratory failure (ARF). Previously COPD diagnoses were established by a physician who evaluated airflow obstruction on spirometry; those with forced expiratory volume in 1 second $\left(\mathrm{FEV}_{1}\right)$ of $70 \%$ predicted or less, and an $\mathrm{FEV}_{1}$ and forced vital capacity ratio of $70 \%$ or less were determined to have COPD. ${ }^{7}$ Spirometry test data were not recorded from the patients' charts. Spirometry testing was not performed for either confirmation or new diagnosis of COPD during ICU stay of patients. Only those patients who were admitted to the ICU for the first time with ARF were evaluated in case of recurrent admissions to the ICU during the study period. Patients were grouped based on ICU mortality (Figure 1).

\section{Data}

Demographics and reasons for ICU admission associated with ARF, such as sepsis/septic shock, pneumonia, pulmonary embolism, and pneumothorax, were recorded from the patients' ICU files. ${ }^{5,8,9}$ Comorbidities, including DM, arrhythmia (ie, atrial fibrillation), hypertension, congestive heart failure, coronary artery disease (CAD), malignancy, and depression were also recorded, ${ }^{10,11}$ as were history of smoking, use of long-term oxygen therapy (LTOT), and long-term mechanical ventilation (MV) (NIV or invasive [IMV]) via tracheostomy. Acute physiology and chronic health evaluation II (APACHE II) scores were calculated as part of the patients' ICU severity index and on admission to the ICU. ${ }^{12}$ Arterial blood gas (ABG) values at the time of ICU admission and discharge were recorded from the patients' file. Serum C-reactive protein (CRP) levels, the application of NIV and/or IMV in the ICU, the lengths of ICU and hospital stays (days), and ICU mortality (mortality during the ICU stay) were recorded at ICU admission and discharge. Reasons for ICU admission were defined as infection (lower respiratory infection), pulmonary embolism, and pneumothorax, and also pneumonia-caused respiratory failure. Reasons for mortality were grouped as pneumonia, lower respiratory tract infection, lung cancer, severe sepsis/septic shock, multi-organ failure, myocardial infarction, and pulmonary embolism.

\section{Definition}

Hypoxic ARF was defined as the ratio of partial arterial oxygen pressure to inspired fractionated oxygen $\left(\mathrm{PaO}_{2} /\right.$ $\left.\mathrm{FiO}_{2}\right)<300$ and partial arterial carbon dioxide pressure $\left(\mathrm{PaCO}_{2}\right)<45 \mathrm{mmHg}$. Hypercapnic/hypoxemic ARF was

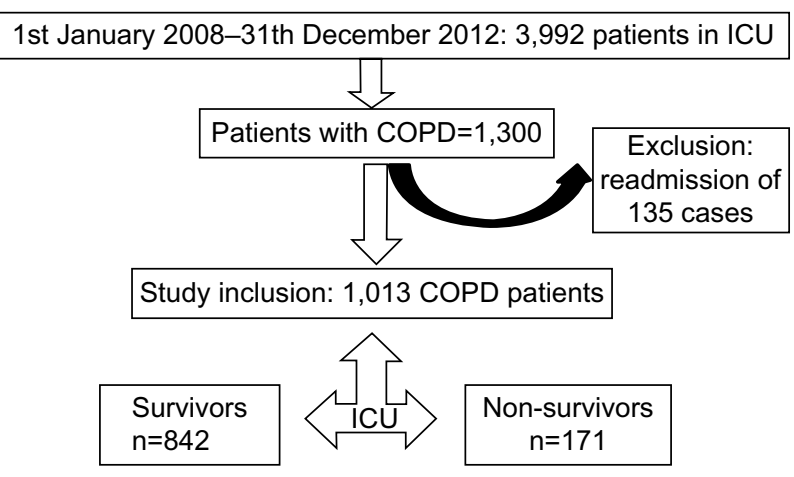

Figure I Flow chart of ICU admission and mortality of COPD patients during 2008-2012.

Abbreviations: COPD, chronic obstructive pulmonary disease; ICU, intensive care unit. 
defined as $\mathrm{PaCO}_{2}>45 \mathrm{mmHg}$ and $\mathrm{PaO}_{2} / \mathrm{FiO}_{2}<300$, and hypercapnic ARF was $\mathrm{PaCO}_{2}>45 \mathrm{mmHg}$ and $\mathrm{PaO}_{2} /$ $\mathrm{FiO}_{2}>300 .^{5,8}$ Patients with $\mathrm{PaCO}_{2}=45 \mathrm{mmHg}$ and patients with $\mathrm{PaO}_{2} / \mathrm{FiO}_{2}=300$ are treated by only medical treatment. The definition of COPD exacerbation due to an infectious origin was defined by the presence of all three of Anthonisen's criteria, as follows: worsening of dyspnea, increased volume of pulmonary secretions (endotracheal and sputum), and increased respiratory secretion purulence. ${ }^{7,13}$

\section{Mechanical ventilation}

Initially, NIV was applied to all COPD patients with hypercapnic respiratory failure except when absolutely contraindicated. ${ }^{14-16}$ NIV contraindications were defined as 1) absolute respiratory arrest and unable to fit mask, and 2) relative, medically unstable (hypotensive shock, uncontrolled cardiac ischemia or arrhythmia, or uncontrolled copious upper gastrointestinal bleeding), agitation, uncooperativeness, inability to protect airway, impaired swallowing, excessive secretions not managed by clearance techniques, multiple (two or more) organ failure, and recent upper airway or upper gastrointestinal surgery. ${ }^{14-16}$

NIV was provided in pressure assist-control mode with ICU mechanical ventilators via a double-tube circuit with a full-face mask. Pressure support (PS) was initially set at 8-10 $\mathrm{cm} \mathrm{H}_{2} \mathrm{O}$ and gradually increased to a maximum of $30 \mathrm{~cm} \mathrm{H} \mathrm{H}_{2} \mathrm{O}$ until the exhaled tidal volume was $5-7 \mathrm{~mL} / \mathrm{kg}$ and guided by patient tolerance. Positive end-expiratory pressure was set at $5 \mathrm{~cm} \mathrm{H}_{2} \mathrm{O}$ and raised or lowered to treat hypoxemia or enhance patient comfort, respectively. $\mathrm{FiO}_{2}$ was adjusted to maintain oxygen saturation $\left(\mathrm{SaO}_{2}\right)$ at $90 \%$. NIV was applied intermittently for periods of 1-4 hours, and initial ABG samples were obtained at the end of the first hour. The duration of each session was determined by ABG value improvement, consciousness level, and patient compliance. The definition of NIV failure in hypercapnic patients was no $\mathrm{pH}$ improvement, no change or a rise in breathing frequency after 1-2 hours, and lack of cooperation. For hypoxic COPD patients, failure was considered as no, or a minimal, rise in $\mathrm{PaO}_{2} / \mathrm{FiO}_{2}$ after $1-2$ hours $(<200) .{ }^{14} \mathrm{IMV}$ was applied in the presence of absolute or relative contraindications for NIV, as mentioned above. The Richmond agitation sedation scale was used for infusion and assessment of the daily need for sedation. ${ }^{17}$ When patients met the previously described criteria for weaning, the PS ventilation mode was used and gradually decreased (1-2 $\mathrm{cm} \mathrm{H}_{2} \mathrm{O}$ every $1-2$ hours). ${ }^{20}$ When the PS reached $8-10 \mathrm{~cm} \mathrm{H}_{2} \mathrm{O}$ and positive end-expiratory pressure was 0 or $<5 \mathrm{~cm} \mathrm{H}_{2} \mathrm{O}$, the patient progressed to spontaneous breathing trials using a T-piece with oxygen support. The T-piece trial duration was 30 minutes, after which the patients were extubated. NIV was then applied in cases of moderate respiratory distress if there was no contraindication. ${ }^{18}$

\section{Bronchodilator and anti-inflammatory treatment in the ICU}

A short-acting $\beta 2$ agonist (salbutamol, $100 \mu \mathrm{g}$ per puff) and ipratropium bromide (100 $\mu \mathrm{g} / 20 \mu \mathrm{g}$ per puff) were given every $2-4$ hours (4-10 puffs) via a metered dose inhaler chamber (Aerovent, Altech ${ }^{\circledR}$; Altera Firm, Izmir, Turkey) when the patients were under NIV or IMV. A nebular form of salbutamol ( $2.5 \mathrm{mg} / 2.5 \mathrm{~mL}$ per nebule) was given every 15 minutes to 4 hours, or ipratropium bromide/salbutamol $(0.5 \mathrm{mg} / 3.01 \mathrm{mg} / 2.5 \mathrm{~mL}$ per nebule) was given every 2-4 hours for patients breathing without MV support. Longacting $\beta 2$ agonists were not used in COPD patients with ARF in the ICU. Intravenous methylprednisolone (40-60 mg) was given one to two times daily as an anti-inflammatory for those patients unable to take oral medications or with impaired gastrointestinal absorption. The steroid dose was gradually tapered and then discontinued over 7-10 days. Methylxanthines (theophylline and aminophylline) were not administered. All patients received oxygen for COPD, as well as medication to treat the underlying cause of ICU admission or ARF and comorbidities, such as antibiotics, antiarrhythmic drugs, or anticoagulant therapies. ${ }^{19}$

\section{Statistical analysis}

A descriptive analysis was performed to investigate patient demographics and ICU data. Groups were compared with Mann-Whitney $U$-tests or Student's $t$-tests for nonparametric continuous or parametric continuous variables, respectively. Chi-square tests were employed for dichotomous variables. The median with interquartile range was employed for nonparametric continuous variables, and mean \pm standard deviation was used for parametric continuous variables. Count and percentage were used when applicable. Binary logistic regression analyses were performed to predict COPD patient ICU mortality. We included the variables that were of statistical significance following univariate analyses in the model. A $P$-value $<0.05$ was accepted as statistically significant. The SPSS-20 portable package program was used to perform statistical analyses.

\section{Results}

During the study period, a total of 3,992 patients were admitted to the ICU. After excluding patients who were 
readmitted, 1,013 (25\%) patients with COPD were included in the study. ICU mortality was observed in 171 (16.9\%) cases (Figure 1). All patients were divided into two groups: survivors and non-survivors. The groups' demographic and ICU data are summarized in Table 1. Both groups had similar gender ratios with male predominance. Survivors were significantly more overweight than non-survivors $(P<0.001)$. Among the five comorbidities, hypertension was the most common in both groups. While the rates of DM were similar in both groups, the other comorbidities were significantly more frequent in non-survivors (Table 1). In addition, non-survivors had a significantly higher rate of home device use (LTOT, NIV) and were more likely to have been tracheostomized. APACHE II scores, $\mathrm{PaO}_{2} / \mathrm{FiO}_{2}$, bicarbonate $\left(\mathrm{HCO}_{3}\right)$ level in $\mathrm{ABGs}$, and serum CRP values at ICU admission were significantly worse in non-survivors compared with survivors (Table 1). Infection was the major reason for ICU admission in both groups, and the presence of pneumonia was significantly higher in

Table I Demographics and ICU data

\begin{tabular}{|c|c|c|c|}
\hline & $\begin{array}{l}\text { Survivors } \\
n=842\end{array}$ & $\begin{array}{l}\text { Non-survivors } \\
n=|7|\end{array}$ & $P$-value \\
\hline \multicolumn{4}{|l|}{ Demographics } \\
\hline Female/male & $224 / 618$ & $40 /|3|$ & 0.38 \\
\hline Age, mean (SD) & & & 0.07 \\
\hline $4 I-65$ years & $278(33.0)$ & $41(24.0)$ & \\
\hline $66-80$ years & $458(54.4)$ & $105(61.4)$ & \\
\hline 81 years and above & $106(12.6)$ & $25(14.6)$ & \\
\hline $\mathrm{BMI}$, mean $\pm \mathrm{SD}$ & $26 \pm 6$ & $23 \pm 6$ & 0.001 \\
\hline \multicolumn{4}{|l|}{ Comorbidities of groups, $n$ (\%) } \\
\hline Hypertension & $283(33.7)$ & $72(42.1)$ & 0.035 \\
\hline CAD & $94(11.2)$ & $47(27.5)$ & 0.001 \\
\hline Arrhythmia & $92(11)$ & $4 I(24)$ & 0.001 \\
\hline DM & $139(16.5)$ & $31(18.1)$ & 0.6 \\
\hline Malignancy & $21(2.5)$ & $17(9.9)$ & $0.00 \mathrm{I}$ \\
\hline Depression & $24(2.9)$ & $12(7)$ & 0.007 \\
\hline Number of hospitalizations in the past year & $\mathrm{I} \pm 2$ & $2 \pm 2$ & 0.001 \\
\hline \multicolumn{4}{|l|}{ Home devices, $\mathbf{n}(\%)$} \\
\hline LTOT & $300(35.6)$ & $98(57.3)$ & 0.001 \\
\hline NIV & $108(12.8)$ & $35(20.5)$ & 0.009 \\
\hline IMV-tracheostomy & $4 \mid(4.9)$ & $16(9.4)$ & 0.002 \\
\hline \multicolumn{4}{|l|}{ ICU data } \\
\hline APACHE II score on ICU admission, mean \pm SD & $19 \pm 6$ & $25 \pm 8$ & 0.001 \\
\hline \multicolumn{4}{|l|}{ Reasons of ICU admission } \\
\hline \multicolumn{4}{|l|}{ COPD exacerbations } \\
\hline Infection of LRT, n (\%) & $547(65)$ & I5I (88.3) & 0.001 \\
\hline Pulmonary Embolism, n (\%) & $39(4.6)$ & 0 & 0.004 \\
\hline Pneumothorax, n (\%) & $11(1.3)$ & $9(5.3)$ & 0.001 \\
\hline Pneumonia, n (\%) & $147(17.5)$ & $94(55)$ & 0.001 \\
\hline \multicolumn{4}{|l|}{ ABG values on the admission to the ICU } \\
\hline $\mathrm{PaO}_{2} / \mathrm{FiO}_{2}$, median $(25 \%-75 \%)$ & $180(130-245)$ & |4| (98-203) & 0.001 \\
\hline $\mathrm{pH}$, mean $\pm \mathrm{SD}$ & $7.30 \pm 0.33$ & $7.29 \pm 0.13$ & 0.64 \\
\hline $\mathrm{PaO}_{2} \mathrm{mmHg}$, median (25\%-75\%) & $72(53.3-97.0)$ & $68.1(51.7-96.5)$ & 0.40 \\
\hline $\mathrm{PaCO}_{2} \mathrm{mmHg}$, mean $\pm \mathrm{SD}$ & $72.5 \pm 20.8$ & $72.1 \pm 26.8$ & 0.84 \\
\hline $\mathrm{HCO}_{3}$ mmol, mean $\pm \mathrm{SD}$ & $34.7 \pm 12.7$ & $31.9 \pm 10.9$ & 0.008 \\
\hline \multicolumn{4}{|l|}{ Respiratory failure } \\
\hline Hypoxemic, n (\%) & $654(77.7)$ & $161(94.2)$ & 0.001 \\
\hline Hypercarbic, n (\%) & $678(80.5)$ & $125(73.1)$ & 0.029 \\
\hline Mixed, n (\%) & $542(64.4)$ & $118(69.6)$ & 0.19 \\
\hline CRP on the admission to the ICU, median ( $25 \%-75 \%)$ & $30(13-73)$ & $86(33-148)$ & 0.001 \\
\hline ICU hospitalization, $\mathrm{n}$ & $7(4-10)$ & $7(3-13)$ & 0.77 \\
\hline Hospitalization, $n$ & $13(8-18)$ & II (5-18) & 0.003 \\
\hline
\end{tabular}

Abbreviations: ABG, arterial blood gas; APACHE II, acute physiology and chronic health evaluation II; BMI, body mass index; CAD, coronary artery disease; COPD, chronic obstructive pulmonary disease; CRP, C-reactive protein; DM, diabetes mellitus; $\mathrm{FiO}_{2}$, fraction of inspired oxygen; ICU, intensive care unit; IMV, invasive mechanical ventilation; LRT, lower respiratory tract; LTOT, long-term oxygen therapy; NIV, noninvasive mechanical ventilation; $\mathrm{PaCO}_{2}$, partial arterial pressure of carbon dioxide; $\mathrm{PaO}_{2}$, partial arterial pressure of oxygen; $\mathrm{SD}$, standard deviation. 
non-survivors $(P<0.001)$ (Table 1$)$. Both groups stayed in the ICU for a similar number of days.

The comorbidity distributions for females and males in each group are summarized in Table 2. Females in both groups had significantly higher rates of DM, hypertension, and depression. The prevalence rates of CAD and arrhythmia were similar for both sexes and groups (Table 2).

Table 3 shows the body mass index (BMI) distributions in both groups. A larger proportion of survivors were obese $(P<0.002)$. Hypertension was significantly more likely in obese survivors $(P<0.001)$ and non-survivors $(P<0.010)$. There were no differences in the rates of CAD and arrhythmias in the different BMI subgroups among survivors and non-survivors. A significantly higher rate of depression was noted in lean non-survivor COPD patients.

Figure 2 shows the reasons for ICU mortality. Death in one patient was attributable to multiple causes. The majority of patients died due to pneumonia, while the least common cause of death was pulmonary emboli.

The requirement for MV (either NIV or IMV) is shown in Figure 3. None of the patients in the survivor group experienced NIV failure. Among the non-survivors, 109 initially received NIV $(n=109)$, and 56 NIV failure patients were intubated to receive IMV. Two non-survivor patients with only oxygen therapy were not intubated for IMV due to the patients' and family members' wishes for end-stage treatment for underlying diseases.

Among the non-survivors, exposure to biomass (mostly using cow feces as home heating source in the Anatolian villages) was only observed in females $(n=21)$. Cigarette smoking history as median packets per year was 40 (30-75) and 50 (40-80) packs/year for female and male COPD patients, respectively.

Figure 4 shows the MV demand and ICU outcome in COPD patients with/without pneumonia in the ICU. The mortality rate of pneumonia COPD patients with IMV was two times greater than in those patients without pneumonia.
Logistic regression analysis was performed to predict mortality among COPD patients in the ICU (Table 4). We included the comorbidities and ICU variables recorded in the logistic regression model. IMV application, BMI index groups, pneumonia, and higher APACHE II score on admission to the ICU were not significant risk factors, whereas CAD, hypertension, and chronic hypoxic respiratory failure were found to be mortality risk factors in the ICU.

Figure 5 shows causal diagram for effect of confounding comorbidities on COPD patients with respiratory failure requiring IMV due to respiratory failure with confounding by comorbidities (arrhythmias, hypertension, chronic hypoxemic respiratory failure, $\mathrm{BMI} \leq 20,>20 \mathrm{~kg} / \mathrm{m}^{2}$ ) and presence of pneumonia.

\section{Discussion}

This study found that CAD, arrhythmia, and hypertension were significant mortality predictors among the comorbidities present in COPD patients admitted to ICU with ARF. Pneumonia and lower respiratory tract infection were the top causes of mortality in these patients. Other than pneumonia, lower respiratory tract infection was the second most common cause. Significant mortality predictors were the application of IMV, a high APACHE II score, admission with pneumonia, $\mathrm{BMI} \leq 20,>20 \mathrm{~kg} / \mathrm{m}^{2}$, and chronic hypoxemic respiratory failure.

\section{Sex and ICU mortality}

The ICU admission and mortality rates were lower in female COPD patients. In a 2012 study conducted by Alaithan et $\mathrm{al}^{20}$ 119 COPD patients admitted to ICU were included; 37\% were female, and there were no significant mortality differences between the sexes. Antonelli Incalzi et $\mathrm{al}^{21}$ carried out a 5-year follow-up study involving $270 \mathrm{COPD}$ patients and reported that $17 \%$ were female. In our study, the population was $26 \%$ female, and the mortality rates were similar between the sexes. Additionally, biomass exposure was more common

Table 2 Comorbidity distribution by sex in both groups

\begin{tabular}{|c|c|c|c|c|c|c|}
\hline & \multicolumn{3}{|c|}{ Survivors, $n=842$} & \multicolumn{3}{|c|}{ Non-survivors, n=|7 | } \\
\hline & $\begin{array}{l}\text { Female } \\
n=224\end{array}$ & $\begin{array}{l}\text { Male } \\
n=618\end{array}$ & $P$-value & $\begin{array}{l}\text { Female } \\
n=40\end{array}$ & $\begin{array}{l}\text { Male } \\
n=|3|\end{array}$ & P-value \\
\hline DM, n (\%) & $60(43.2)$ & $79(56.8)$ & 0.001 & $14(45.2)$ & $17(54.8)$ & 0.002 \\
\hline Hypertension, n (\%) & $107(37.8)$ & $175(62.2)$ & 0.001 & $26(36.1)$ & $46(63.9)$ & 0.001 \\
\hline CAD, n (\%) & $23(24.5)$ & 7I (75.5) & 0.61 & I4 (29.8) & $33(70.2)$ & 0.22 \\
\hline Arrhythmia, n (\%) & 31 (33.7) & $62(66.3)$ & 0.12 & $13(3 \mid .7)$ & $28(68.3)$ & 0.15 \\
\hline Malignancy, n (\%) & $5(22.7)$ & $17(77.3)$ & 0.68 & $0(0)$ & $23(100)$ & 0.004 \\
\hline Depression, n (\%) & $10(41.7)$ & I (58.3) & 0.091 & $6(50)$ & $6(50)$ & 0.024 \\
\hline
\end{tabular}

Note: Percentages are calculated from the sum of both females and males in each survivors or non-survivors group.

Abbreviations: CAD, coronary artery disease; DM, diabetes mellitus. 
Table 3 BMI distributions with comorbidities by group

\begin{tabular}{|c|c|c|c|c|c|c|c|c|}
\hline & \multicolumn{4}{|c|}{ Survivors, $n=842$} & \multicolumn{4}{|c|}{ Non-survivors, n=|7| } \\
\hline & $\begin{array}{l}\text { BMI } \leq 20 \\
n=I \mid 4\end{array}$ & $\begin{array}{l}\text { BMI 20-30 } \\
\mathrm{n}=461\end{array}$ & $\begin{array}{l}\mathrm{BMI} \geq 30 \\
\mathrm{n}=166\end{array}$ & $P$-value & $\begin{array}{l}\text { BMI } \leq 20 \\
n=58\end{array}$ & $\begin{array}{l}\text { BMI 20-30 } \\
n=72\end{array}$ & $\begin{array}{l}\text { BMI } \geq 30 \\
n=18\end{array}$ & $P$-value \\
\hline DM, n (\%) & $10(8)$ & $74(59.2)$ & $41(32.8)$ & 0.002 & $5(20.0)$ & $17(68.0)$ & $3(12.0)$ & 0.076 \\
\hline HT, n (\%) & $15(5.9)$ & $162(63.5)$ & $78(30.6)$ & 0.001 & $14(24.1)$ & $36(62.1)$ & $8(13.8)$ & 0.010 \\
\hline CAD, n (\%) & $10(11.9)$ & 57 (67.9) & $17(20.2)$ & 0.50 & $8(22.2)$ & $22(6 I . I)$ & $6(16.7)$ & 0.055 \\
\hline Arrhythmia, n (\%) & $6(7.0)$ & $61(70.9)$ & $19(22.1)$ & 0.061 & II (3I.4) & $17(48.7)$ & $7(20.0)$ & 0.22 \\
\hline Malignancy, n (\%) & $3(15.0)$ & $10(50.0)$ & $7(35.5)$ & 0.20 & $7(35.0)$ & II (55.0) & $2(10.0)$ & 0.83 \\
\hline Depression, n (\%) & $8(34.8)$ & $12(52.2)$ & $3(13.0)$ & 0.027 & $9(81.8)$ & I (9.I) & I (9.I) & 0.009 \\
\hline
\end{tabular}

Note: Percentages are calculated from the sum of both females and males in each survivors or non-survivors group.

Abbreviations: BMI, body mass index; CAD, coronary artery disease; DM, diabetes mellitus; HT, hypertension.

than cigarette smoking in females, which is in accordance with socioeconomic status in Turkey. Some studies have reported higher incidence rates of comorbidities associated with COPD in females or males. ${ }^{22-24}$ The TORCH study, ${ }^{25}$ which provided important data on COPD mortality, showed that comorbidities and mortality rates were similar between the sexes. In our study, we noted significantly higher incidence rates of DM, hypertension, depression, and arrhythmia in female populations; however, there was no sex difference for CAD. When comparing rates of mortality, DM, hypertension, and depression, we found that they were significantly higher in women. There were no sex differences for the prevalence rates of CAD and arrhythmia.

\section{Age and ICU mortality}

In a systematic review of 28 studies investigating risk factors for mortality of COPD patients in the ICU, the average age of the patients was reported to range from 57 to 72 years. ${ }^{26}$ In two of these well-designed studies with large sample sizes $(n=3,752$ and $n=1,009)$, age was not identified as a mortality predictor. The two studies reported the mean age and

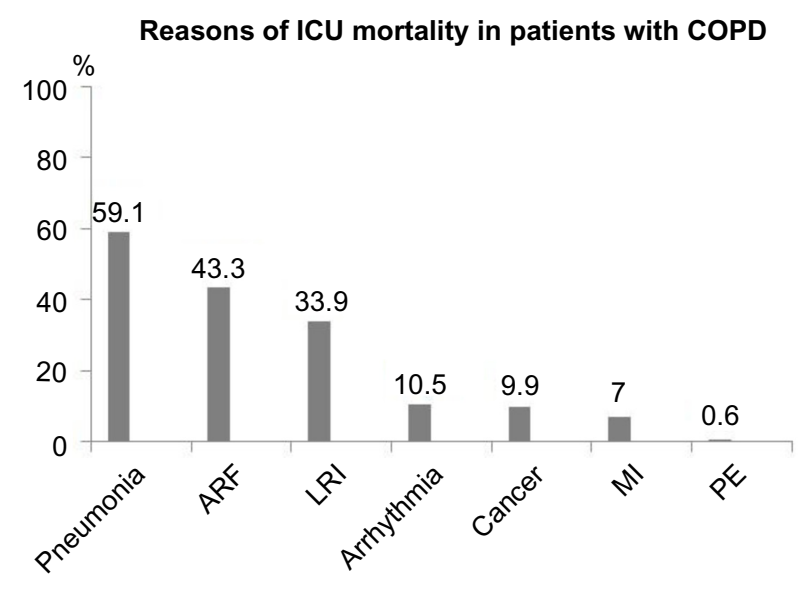

Figure 2 Reasons for ICU mortality among COPD patients.

Abbreviations: ARF, acute respiratory failure; COPD, chronic obstructive pulmonary disease; ICU, intensive care unit; LRI, lower respiratory tract infection; $\mathrm{MI}$, myocardial infarction; PE, pulmonary embolism. mortality rates of these studies were 67.8 years and $38.3 \%$, 70.2 years and $7.8 \%$, respectively. ${ }^{27,28}$ The mean age and mortality rate in the present study were 70 years and $17 \%$. There were no differences between survivor or non-survivor groups in our study for age.

\section{APACHE II score and ICU mortality}

In the systematic review using the APACHE II score as a mortality predictor and investigating COPD mortality, ${ }^{26}$ one study reported a low APACHE II score of 13 and 37\% mortality, whereas another study described a high APACHE II score of 23.8 and $41 \%$ mortality. ${ }^{29,30}$ In our study, the mean APACHE II score was 20.4, and the mortality rate was $17 \%$. Mean APACHE II score was significantly higher in the nonsurvivor group in our study.

\section{Comorbidity and ICU mortality}

Cardiovascular comorbidities (hypertension, CAD, arrhythmia, and heart failure) are the most common comorbidities of COPD. In our study, the rates for hypertension, CAD, and arrhythmia were $35 \%, 14 \%$, and $13 \%$, respectively. Mortality is reportedly increased in the presence of comorbid cardiovascular diseases. ${ }^{23,31}$ In their study of 20,296 COPD

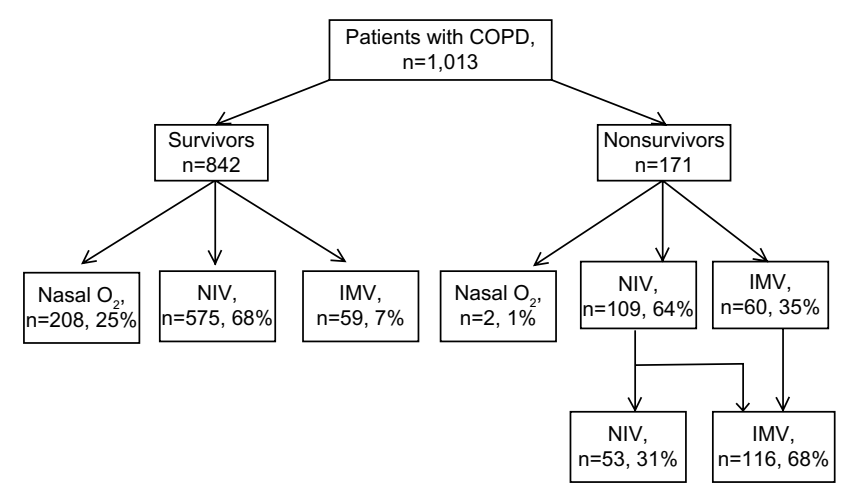

Figure 3 Application of IMV and NIV to survivor and non-survivor groups. Abbreviations: COPD, chronic obstructive pulmonary disease; IMV, invasive mechanical ventilation; NIV, noninvasive mechanical ventilation. 


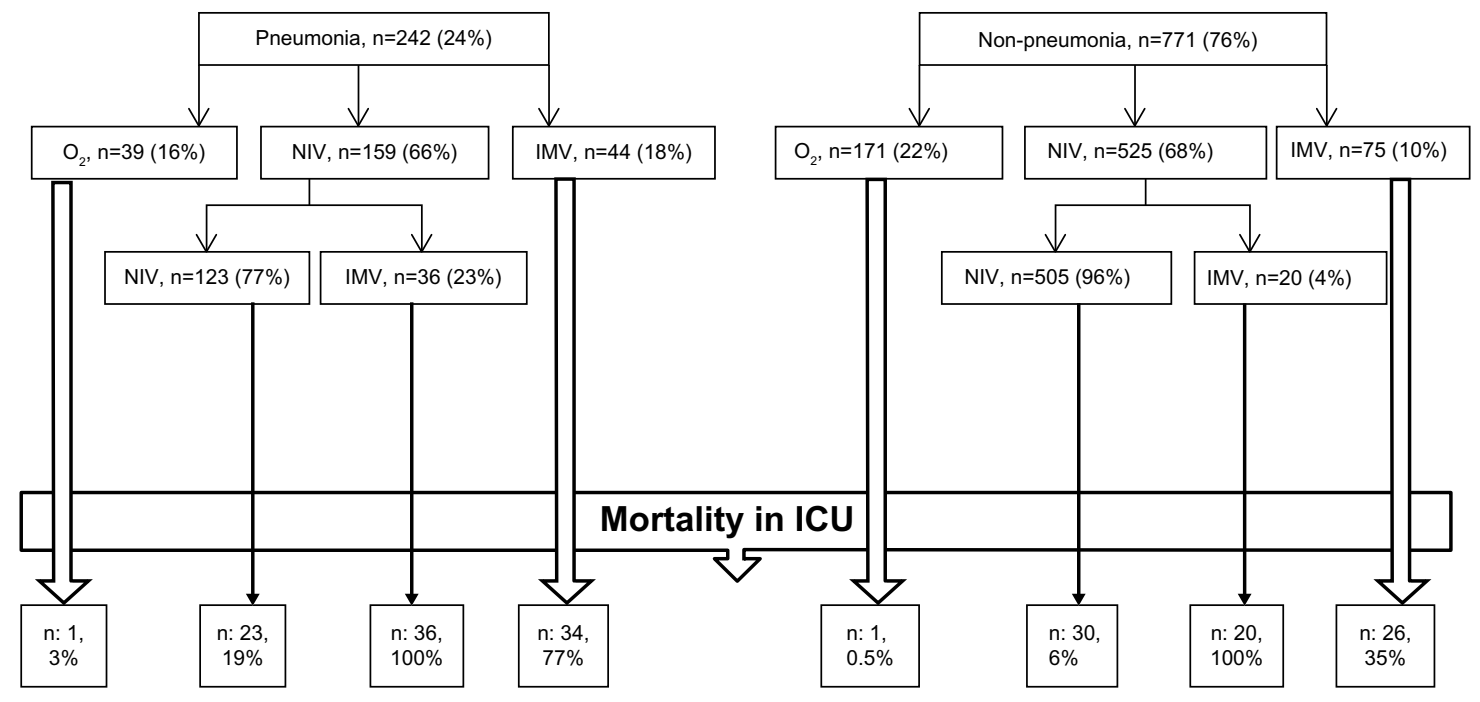

Figure 4 Mechanical ventilation demand and ICU outcome in COPD patients with/without pneumonia in the ICU.

Abbreviations: COPD, chronic obstructive pulmonary disease; ICU, intensive care unit; IMV, invasive mechanical ventilation; NIV, noninvasive mechanical ventilation.

patients, Mannino et $\mathrm{al}^{23}$ found DM and hypertension incidences of $12.7 \%$ and $40.1 \%$, respectively. They found an overall 5 -year mortality of $5.9 \%$, which was significantly increased by DM and cardiovascular comorbidities. Almagro et $\mathrm{a}^{31}$ assessed comorbidities in 398 COPD patients and reported that the most frequent were hypertension, DM, and CAD, with respective incidences of $55 \%, 26 \%$, and $17 \%$. In another study, the rates of hypertension and CAD were $28 \%$ and $10 \%$, respectively, and right ventricular hypertrophy was found to be a risk factor for mortality. ${ }^{21}$ In the present analysis, hypertension was the most frequent cardiac comorbidity (42\%), and the CAD and arrhythmia incidence rates were $22 \%$ and $24 \%$, respectively. Notably, CAD and arrhythmia were twice as common in non-survivor COPD patients. We determined that $\mathrm{CAD}$ increased ICU mortality 2.9 -fold, while

Table 4 Mortality in ICU - logistic regression analysis of COPD patients

\begin{tabular}{llll}
\hline & Odds ratio & $\mathbf{9 5 \%} \mathbf{C l}$ & P-value \\
\hline IMV & 27.71 & $15.67-49.03$ & 0.001 \\
BMI $\leq 20 \mathrm{~kg} / \mathrm{m}^{2}$ & 6.63 & $3.45-12.74$ & 0.001 \\
Pneumonia & 5.09 & $2.96-8.76$ & 0.001 \\
in ICU admission & & & \\
CAD & 2.92 & $1.52-5.58$ & 0.001 \\
Arrhythmia & 2.70 & $1.40-5.22$ & 0.003 \\
Chronic hypoxic RF & 2.60 & $1.53-4.40$ & 0.001 \\
Hypertension & 2.17 & $1.22-3.85$ & 0.008 \\
APACHE II score & 1.07 & $1.03-1.11$ & 0.001 \\
on ICU admission & & & \\
\hline
\end{tabular}

Abbreviations: APACHE II, acute physiology and chronic health evaluation II; $\mathrm{BMI}$, body mass index; CAD, coronary artery disease; $\mathrm{Cl}$, confidence interval; COPD, chronic obstructive pulmonary disease; ICU, intensive care unit; IMV, invasive mechanical ventilation; RF, respiratory failure. arrhythmia and hypertension increased mortality $2.7-$ and 2.2 -fold, respectively.

Although diabetes is one of the most frequently observed comorbidities in COPD patients, only about $10 \%$ of diabetic patients have COPD. ${ }^{6,32,33}$ Antonelli Incalzi ${ }^{21}$ et al reported a $14 \%$ incidence of DM in COPD patients. Mannino et $\mathrm{al}^{23}$ found that COPD patients with diabetes and cardiovascular comorbidities had higher rates of hospitalization and mortality. In our study, the rate of DM was similar (17\%), but there was no statistically significant difference in terms of mortality between COPD patients with and without DM.

\section{$\mathrm{BMI}$ and ICU mortality}

BMI is included in the BODE (BMI, airflow obstruction, dyspnea, exercise capacity) mortality index due to increased

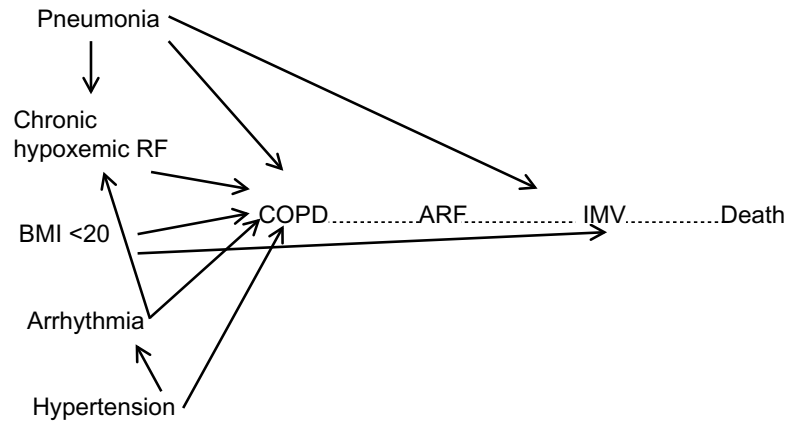

Figure 5 Causal diagram for the effect of confounding comorbiditidies on COPD patients with respiratory failure requiring IMV.

Abbreviations: ARF, acute respiratory failure; BMI, body mass index; COPD, chronic obstructive pulmonary disease; IMV, invasive mechanical ventilation; RF, respiratory failure. 
mortality of COPD patients whose BMI score is $<40 \mathrm{~kg} / \mathrm{m}^{2}{ }^{2}{ }^{34}$ A recent study of 94 intubated patients investigated the effect of BMI on weaning trials. ${ }^{35}$ Within this study, patients were stratified into three groups (BMI $\leq 20 \mathrm{~kg} / \mathrm{m}^{2}$, lean; BMI $21-29 \mathrm{~kg} / \mathrm{m}^{2}$, normal; BMI $\geq 30 \mathrm{~kg} / \mathrm{m}^{2}$, obese), and weaning in the lean group was difficult or even impossible. ${ }^{35}$ On the other hand, a study showing no correlation between weaning difficulty and BMI was also published. ${ }^{36}$ In our study, having a BMI $\leq 20 \mathrm{~kg} / \mathrm{m}^{2}$ increased ICU mortality 6.6-fold.

\section{Chronic hypoxemic respiratory failure and mortality}

Six studies have examined chronic hypoxemic respiratory failure and reported that LTOT use after ICU discharge is a mortality predictor. ${ }^{37-42}$ The strongest study among these was published in 2009; it followed 832 patients for 180 days, starting from the ICU, and reported a mortality rate of $37.9 \%$. Chronic hypoxemic respiratory failure has also been found to be an independent mortality predictor. ${ }^{37}$ In our study, the rate of LTOT use was $39.3 \%$ in all patients and $57.3 \%$ in the mortality group. Chronic respiratory failure was found to increase ICU mortality 2.6-fold.

\section{Pneumonia and ICU mortality}

Although the risk of pneumonia in COPD mortality attracted attention due to the TORCH (towards a revolution in COPD health) study, conflicting results have been reported elsewhere. ${ }^{25,26}$ One of the four studies that reported that pneumonia is not a factor for ICU mortality determined that the presence of pulmonary infiltrates were associated with the terminal stage of COPD and mortality. ${ }^{30,43-45}$

However,Wildman et $\mathrm{al}^{27}$ indicated in their well-designed study that the presence of pneumonia was strongly correlated with ICU mortality of COPD patients. Results from a recent study conducted in Turkey described the mortality of patients diagnosed with community-acquired pneumonia at ICU admission. ${ }^{45} \mathrm{We}$ found a five-fold mortality increase in patients with pneumonia. Culture specimens were taken from $80 \%$ of patients, and $75 \%$ were positive. Almost all the pathogens isolated from cultures were antibiotic resistant, which may be due to frequent and chronic use of antibiotics and hospitalizations. In a Turkish multicenter study, culture positivity was detected in $20 \%$ of cases, and resistant pathogens were noted in $70 \%$ of these patients. ${ }^{45}$ We observed fewer resistant pathogens compared with that study; however, Cilli et $\mathrm{al}^{45}$ did not report the rate of resistant pathogens among the $80 \%$ of patients for whom culture samples were not collected. In our study, the presence of pneumonia was found to predict mortality. Cilli et $\mathrm{al}^{45}$ indicated that application of IMV in COPD patients with pneumonia increased mortality 1.6-fold, while NIV application decreased the mortality rate by $72 \%$. In the subanalysis of the two groups concerning the presence of pneumonia, the need for IMV therapy was two times greater in patients with pneumonia. Also, the rates of IMV therapy and NIV failure were five times greater in patients with pneumonia who had received NIV as an initial treatment. Additionally, a 2.2-fold higher mortality was observed in COPD patients who received IMV therapy with pneumonia compared with patients on IMV therapy without pneumonia. A three-fold greater mortality rate was noted in patients treated with NIV who had pneumonia compared with patients without pneumonia. Considering these results, the presence of resistant pathogens that cause pneumonia is thought to increase ICU mortality in COPD patients.

\section{MV and ICU mortality}

Decreased hospital mortality of COPD patients with ARF who received NIV was reported in a meta-analysis that included 979 COPD patients from 14 studies. ${ }^{46}$ The intubation rate of patients with initial NIV treatment ranged from $9 \%$ to $56 \%$, while the mean intubation rate was $35 \%$. The relative risk of mortality ranged from $13 \%$ to $100 \%$, with an average of $45 \% .{ }^{46}$ In the same meta-analysis, length of hospital stay was significantly decreased (mean 1.9 days in ten studies) in patients who received NIV treatment. ${ }^{46}$ In our study, NIV was applied unless there were contraindications, and $8.2 \%$ of patients required intubation. The mortality rate was $7.7 \%$ in patients who received NIV, and these patients were terminal and did not want to be intubated. Notably, there was a $100 \%$ mortality rate in patients who were intubated after NIV failure. Overall, $11.7 \%$ of patients were intubated at the time of admission, and half of these patients died. A mortality risk analysis of our data showed that the need for IMV treatment increased mortality 28-fold.

\section{Septic shock, multiple organ failure, and mortality}

Exacerbation of COPD and pneumonia were previously reported as the most common reasons for mortality in patients with ARF who were admitted to the ICU. ${ }^{26,45,46}$ Data regarding the definition of sepsis and septic shock in COPD patients are limited. We investigated systemic inflammatory response syndrome and sepsis criteria in our study, and septic shock at admission was detected in half of the patients in the 
non-survivor group. Multi-organ failure was observed in 75\% of patients in the non-survivor group.

\section{ABG analysis and ICU mortality}

Although existing studies have indicated an increased requirement for IMV treatment below $\mathrm{pH} 7.25$ during NIV treatment, other studies reported that NIV can be successful when safe monitoring in the ICU is possible. ${ }^{47}$ Deep acidosis on $\mathrm{ABG}$ analyses was not observed in our patients. There were no significant differences in $\mathrm{PaCO}_{2}$ or $\mathrm{pH}$ values of patients in the two groups, but $\mathrm{O}_{2}$ demand $\left(\mathrm{PaO}_{2} / \mathrm{FiO}_{2}\right)$ and $\mathrm{HCO}_{3}$ values were significantly lower in the non-survivor group. Messer et $\mathrm{al}^{26}$ reported that $\mathrm{HCO}_{3}$ levels $<20 \mathrm{mmol}$ were associated with increased mortality.

\section{CRP and mortality}

In a well-designed study conducted by Rammaert et al, ${ }^{38} \mathrm{CRP}$ was found to be a significant mortality predictor. Although we found that CRP was higher in the non-survivor group, it was not a mortality predictor in the logistic regression analysis.

\section{Limitations}

Our study was retrospective and carried out at a single center. However, we believe that the study provides valuable clinical information for assessing ICU outcomes of COPD patients, as the study population was large and disease specific. COPD severity and spirometry results were not recorded, and the presence of osteoporosis was not recorded because there were no objective diagnostic test results on file. Missing data collection was not possible for the mortality group given the study's retrospective nature. Nevertheless, the radiological and clinical findings of patients were consistent with COPD.

\section{Conclusion}

Nutrition protocol regulation is useful for improving the quality of life of COPD patients and their family. Follow-up of spirometry with BMI measurements and pulmonary rehabilitation are recommended for COPD patients who are admitted to the ICU with ARF. Because the presence of CAD and arrhythmia increase ICU mortality, it is recommended that the target $\mathrm{SaO}_{2}$ for these patients should be $>92$. NIV can be risky for patients with hypoxia-induced arrhythmia, and treatments must be performed to address the underlying cause. Common reasons for COPD patient ICU admission are infection and the presence of resistant pathogens. Because these factors increase mortality, infection treatment protocols and rational antibiotic use should be planned. Data from this study and mortality predictors for COPD patients in the ICU will be helpful for identifying new treatment modalities. Finally, this study is important to determine the significance of long-term nutrition protocols, arrhythmia diagnosis/treatment, and rational antibiotic use in COPD patients.

\section{Disclosure}

The authors have not had any industry relationships for the past 2 years and do not have any conflict of interest in this work.

\section{References}

1. Menezes AM, Perez-Padilla R, Jardim JR, et al. Chronic obstructive pulmonary disease in five Latin American cities (the PLATINO study): a prevalence study. Lancet. 2005;366(9500):1875-1881.

2. Appleton S, Jones T, Poole P, et al. Ipratropium bromide versus longacting beta-2 agonists for stable chronic obstructive pulmonary disease. Cochrane Database Syst Rev. 2006;3:CD006101.

3. Barr RG, Bourbeau J, Camargo CA. Tiotropium for stable chronic obstructive pulmonary disease. Cochrane Database Syst Rev. 2005;2: CD002876.

4. Tashkin DP, Celli B, Senn S, et al. A 4-year trial of tiotropium in chronic obstructive pulmonary disease. N Engl J Med. 2008;359:1543-1554.

5. International Consensus Conferences in Intensive Care Medicine noninvasive positive pressure ventilation in acute respiratory failure. Am J Respir Crit Care Med. 2001;163:283-291.

6. Global Initiative for Chronic Obstructive Lung Disease (GOLD). 2013 (update) http://www.goldcopd.com. Accessed April 17, 2014.

7. Buist AS, Vollmer WM, Sullivan SD, et al. The Burden of Obstructive Lung Disease Initiative (BOLD): rationale and design. COPD. 2005;2:227-283.

8. World Health Organization. Global Alliance against Chronic Respiratory Diseases. http://www.who.int/entity/gard/en. Accessed September 8, 2014.

9. Ministry of Health General Directorate of Primary Health Care: Turkey Chronic Respiratory Disease Prevention and Control Program, Ankara 2009.

10. Kocabas A, Hancioglu A, Turkyilmaz S, et al. Prevalence of COPD in Adana, Turkey (BOLD-Turkey Study). Proc Am Thorac Soc. 2006;3(Abstract Issue):A543.

11. Buist AS, McBurnia MA, Vollmer WM, et al; BOLD Collaborative Research Group. International variation in the prevalence of COPD (The BOLD Study): a population-based prevalence study. Lancet. 2007;370: 741-750.

12. Chapman KR, Mannino DM, Soriano JB, et al. Epidemiology and cost of chronic obstructive pulmonary disease. Eur Respir J. 2006;27:188-207.

13. World Health Organization. World Health Report 2004: changing history. Geneva: World Health Organization; 2004.

14. Nava S, Hill N. Non-invasive ventilation in acute respiratory failure. Lancet. 2009;374(9685):250-259.

15. Ambrosino N, Vagheggini G. Non-invasive ventilation in exacerbations of COPD. Int J Chron Obstruct Pulmon Dis. 2007;2(4):471-476.

16. Ambrosino N, Vagheggini G. Noninvasive positive pressure ventilation in the acute care setting: where are we? Eur Respir J. 2008;31(4): 874-886.

17. Sessler CN, Gosnell MS, Grap MJ, et al. The Richmond AgitationSedation Scale: validity and reliability in adult intensive care unit patients. Am J Respir Crit Care Med. 2002;166(10):1338-1344.

18. Boles JM, Bion J, Connors A, et al. Weaning from mechanical ventilation. Eur Respir J. 2007;29(5):1033-1056.

19. Global Initiative for Chronic Obstructive Lung Disease. Global strategy for diagnosis, management, and prevention of COPD (updated 2008) (http://www.goldcopd.org). Accessed July 17, 2014. 
20. Alaithan AM, Memon JI, Rehmani RS, Qureshi AA, Salam A. Chronic obstructive pulmonary disease: hospital and intensive care unit outcomes in the Kingdom of Saudi Arabia. Int J Chron Obstruct Pulmon Dis. 2012;7:819-823.

21. Antonelli Incalzi R, Fuso L, De Rosa M, et al. Co-morbidity contributes to predict mortality of patients with chronic obstructive pulmonary disease. Eur Respir J. 1997;10:2794-2800.

22. Ekström MP, Jogréus C, Ström KE. Comorbidity and sex-related differences in mortality in oxygen-dependent chronic obstructive pulmonary disease. PLoS One. 2012;7(4):e35806.

23. Mannino DM, Thorn D, Swensen A, Holguin F. Prevalence and outcomes of diabetes, hypertension and cardiovascular disease in COPD. Eur Respir J. 2008;32:962-969.

24. de Torres JP, Cote CG, Lopez MV, et al. Sex differences in mortality in patients with COPD. Eur Respir J. 2009;33(3):528-535.

25. Celli B, Vestbo J, Jenkins CR, et al. Sex differences in mortality and clinical expressions of patients with chronic obstructive pulmonary disease: the TORCH experience. Am J Respir Crit Care Med. 2011;183(3):317-322.

26. Messer B, Griffiths J, Baudouin SV. The prognostic variables predictive of mortality in patients with an exacerbation of COPD admitted to the ICU: an integrative review. QJM. 2012;105(2):115-126.

27. Wildman M, Harrison DA, Brady AR, Rowen K. Case mix and outcomes for admissions to UK adult, general critical care units with chronic obstructive pulmonary disease: a secondary analysis of the ICNARC Case Mix Programme Database. Crit Care. 2005;9:S38-S48.

28. Berkius J, Nolin T, Mardh C, Karlstrom G, Walther SM. Characteristics and long-term outcome of acute exacerbations in chronic obstructive pulmonary disease: an analysis of cases in the Swedish Intensive Care Registry during 2002-2006. Acta Anaesthesiol Scand. 2008;52: 759-765.

29. Khilnani GC, Banga A, Sharma SK. Predictors of mortality of patients with acute respiratory failure secondary to chronic obstructive pulmonary disease admitted to an intensive care unit: a one year study. $B M C$ Pulm Med. 2004;4:12.

30. Motiani P, Ahuja S, Ramachandran R. Clinical course and hospital outcome of patients with COPD admitted to an ICU for ventilatory support. J Anaesth Clin Pharmacol. 2010;26:208-212.

31. Almagro P, Lopez Garcia F, Cabrera F, et al. Comorbidity and genderrelated differences in patients hospitalized for COPD. The ECCO study. Respir Med. 2010;104:253-259.

32. Kerr EA, Heisler M, Krein SL, et al. Beyond comorbidity counts: how do comorbidity type and severity influence diabetes patients' treatment priorities and self-management? J Gen Intern Med. 2007;22(12): 1635-1640.

33. Caughey GE, Roughead EE, Vitry AI, McDermott RA, Shakib S, Gilbert AL. Comorbidity in the elderly with diabetes: Identification of areas of potential treatment conflicts. Diabetes Res Clin Pract. 2010; 87(3):385-393.
34. Celli BR, Cote CG, Marin JM, et al. The body-mass index, airflow obstruction, dyspnea, and exercise capacity index in chronic obstructive pulmonary disease. $N$ Engl J Med. 2004;350:1005-1012.

35. Li-dong S, Chang-sheng G, Zi-yu Z. Explore the influence of BMI in the optimal time of weaning from sequential mechanical ventilation for severity chronic obstructive pulmonary disease. BMC Emerg Med. 2013;13(Suppl 1):S1.

36. Anzueto A, Frutos-Vivar F, Esteban A, et al; Ventila group. Influence of body mass index on outcome of the mechanically ventilated patients. Thorax. 2011;66(1):66-73.

37. Wildman MJ, Sanerson C, Groves J, et al. Predicting mortality for patients with exacerbations of COPD and Asthma in the COPD and Asthma Outcome Study (CAOS). QJM. 2009;102:389-399.

38. Rammaert B, Verdier N, Cavestri B, Nseir S. Respirology. Procalcitonin as a prognostic factor in severe acute exacerbation of chronic obstructive pulmonary disease. Respirology. 2009;14(7):969-974.

39. Raurich JM, Perez J, Ibanez J, Roig S, Batle S. In-hospital and 2-year survival of patients treated with mechanical ventilation for acute exacerbation of COPD. Arch Bronchoneumol 2004;40:295-300.

40. Yang S, Tan K-L, Devanand A, Fook-Chong S, Eng P. Acute exacerbation of COPD requiring admission to the intensive care unit. Respirology. 2004;9:543-549.

41. Moran JL, Green JV, Homan SD, Leeson RJ, Leppard PI. Acute exacerbations of chronic obstructive pulmonary disease and mechanical ventilation: a reevaluation. Crit Care Med. 1998;26:71-78.

42. Rieves RD, Bass D, Carter RR, Griffith JE, Norman JR. Severe COPD and acute respiratory failure. Correlates for survival at the time of tracheal intubation. Chest. 1993;104:854-860.

43. Rello J, Rodriguez A, Torres A, et al. Implication of COPD in patients admitted to the intensive care unit by community-acquired pneumonia. Eur Respir J. 2006;27:1210-1216.

44. Mohan A, Premanand R, Reddy LN, et al. Clinical presentation and predictors of outcome in patients with severe acute exacerbation of chronic obstructive pulmonary disease requiring admission to intensive care unit. BMC Pulm Med. 2006;6:27.

45. Cilli A, Erdem H, Karakurt Z, et al. Community-acquired pneumonia in patients with chronic obstructive pulmonary disease requiring admission to the intensive care unit: risk factors for mortality. J Crit Care. 2013; 28(6):975-979.

46. Quon BS, Gan WQ, Sin DD. Contemporary management of acute exacerbations of COPD: a systematic review and metaanalysis. Chest. 2008;133(3):756-766.

47. Conti G, Antonelli M, Navalesi P, et al. Noninvasive vs conventional mechanical ventilation in patients with chronic obstructive pulmonary disease after failure of medical treatment in the ward: a randomized trial. Intensive Care Med. 2002;28:1701-1707.
International Journal of COPD

\section{Publish your work in this journal}

The International Journal of COPD is an international, peer-reviewed journal of therapeutics and pharmacology focusing on concise rapid reporting of clinical studies and reviews in COPD. Special focus is given to the pathophysiological processes underlying the disease, intervention programs, patient focused education, and self management protocols.
Dovepress

This journal is indexed on PubMed Central, MedLine and CAS. The manuscript management system is completely online and includes a very quick and fair peer-review system, which is all easy to use. Visit http://www.dovepress.com/testimonials.php to read real quotes from published authors. 